\title{
IV.-THE SUBCONSCIOUS FACTORS OF MENTAL PROCESS CONSIDERED IN RELATION TO THOUGHT (I.).
}

\author{
BY A. M. BODKIN.
}

1. Tht ides of subconscious or unconscious mental factors has been treated in very various ways by different writers. The conception of unconscious mind has an important place in metaphysical discassion. Fren in psychology the introduction of unconscious factors has often been upheld for reasons which appear to be partly of a metaphysical character. Unconscious presentations have been postulated both as causes and as effects of observable phenomena.' They have been regarded as causes of such phenomena as those of memory, especislly by writers who hold with Leibuiz that "one perception can in a natural way come only from another perception," $z$ and who are reluctant to assign merely material modifications as conditions within psychological explanation. Unconscious psychical factors have, again, been postulated as effects of all such physiological changes-actions or affections of the organism-as at other times or at higher degrees of intensity have been found to be accompanied by consciousness. Thus G. H. Lewes: "we must have had these sensations and idess in spite of their being unconscious states, because it is certain that we had the organic states which are their physiological conditions of production, and these cannot exist without sensations and ideas (the products) for causes necessarily involve effects" s

At the present time the conception of subconscions, or unconscious, mental modifications of this kind, wholly beyond the range of introspection, seems to meet with little favour among psychologists. It is urged that for psychology it is sufficient to take account. on the one hand, of the phenomen it

' ('i. Brentuno, l'nychluhyir, Buch ii., Capitel 2, s 45.

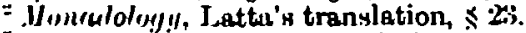

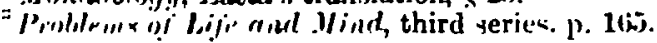


of consciousness so far as verifiable by introspection, and on the other of bodily changes so far as these can be observed or inferred. Any inquiry as to the ultimate nature of these bodily changes, as, whether they can be held to possess, even when unconscious, some prychical aspect, may be abandoned to metaphysics.

Thus Mr. McDougall ${ }^{1}$ orges that by assigning consciousness only where we are compelled by introspection to assign it, and elsewhere spesking of nervous processes simply, we shall avoid obscurities of statement and have a method well adspted for making use of the constantly growing body of knowledge supplied by physiology and psycho-physical experiment.

There is however a different sense in which the idea of the subconscious is employed. It may refer not to supposed modifications of the soul altogether beyond the reach of introspection, bat to grades of consciousness, or modes of presentation, less organised, or in some way less distinct and obvious, than those which are taken as typical;-modes which are unconscious only relatively to clearer formas. To the recognition of such presentations we may indeed hardly be 'compelled by introspection,' since by their very nature these elements are readily passed over and hard to verify; yet the consideration of them may nevertheless be necessary for a complete account of the structure and development of intellectual life.

It is the design of the present essay to deal with subconscious factors of this latter kind, in their relation to the thought process : to consider, first, the distinction of what may be called feeling, or sentience, from the contents of thought or clear cognitive consciousness: and, following upon this, to speak of that organisation of sense-material which may take place through bodily activity apart from the work of thought. The latter part of the paper will be occupied with a consideration of the manner in which mental factors of different degrees of organisation may be operative in inferential jadgment without coming explicitly before the mind: also the nature of the process by which such factors become explicit will be discussed.

2. In considering the distinction between the material of sense and the formed structure of knowledge, it is to Kant that we natarally tarn as the most famous historical exponent of the subject. Prior to Kant there had been a general dis-

$$
\text { 'Jlex, rol. vii., N.S.. p. } 2.3 .
$$


position among those undertaking the analysis of mind to regard knowledge as something given in the mere action of stimuli upon the senses. In sach writers as Locke and Hume we find hardly any recognition of those intellectual implications that accompany even the sinplest act of senseknowledge as this takes place in the developed mind. Locke has, indeed, an interesting reference to certain lower grades of conscionsness where attention, and thus clear knowledge, is lacking. Ideas, he says, may be "as faint shadows that make no impression" "; sensations may fail to be "taken notice of in the understanding " ${ }^{3}$ of the operations of our own minds, which pass continually, we have at first no ideas -no knowledge,- - they are "like flosting visions" " till the understanding turns inward upon itself in reflexion.

But Locke can say little as to what is involved in this process of attention or reflexion which he regards as neces. sary to knowledge. It is conceived by him simply on the anslogy of vision. As the eyes turn to various objects within the vigible field, so the mind turns, takes notice of the varions impressions conveyed into it, or of its own operations, and forthwith "cannot but have plain and clear ideas of them" Qualities and processes alike are known as such in the passive reception of them by the mind. Berkeley and Hume in their closer examination of what is given in sensstion still retain the idea of passively accepted items of knowledge, which are indeed wrought into more elaborate constructions by the mind, but which from the first appesr as quite definite knowable units.

In the work of Reid a different view of sensation is to be found. The having of a sensation, Reid insists, is a quite different thing from the knowledge of a sense-quality by means of the sensation. The latter is a judgment involving reference both to self and to an external object.' It is with such judgments that knowledge begins.

Kant's contention concerning knowledge, though worked out with far more elaboration than that of Reid, appears in important respects similar. Knowledge is shown as a mental construction; it is no simple sum of given elements, but, as it were, a woven texture, within which each element has a certain setting according to a plan that pervades the whole. Nothing is known in isolstion, but, os Reid insisted, certain permenent implicstions accompsny every act of knowledge. The matter of sense is received into the forms of the under-

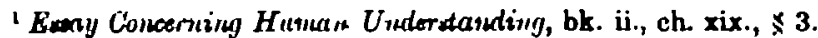

'Ibid., bk. ii., ch. ix., $\$ 4 . \quad$ Ibill., bk. ii., ch. i., $\$ 8$. 
standing and is thus given a place within a world of objects related one to another and to the self.

3. How then are we to think of the nature of the sensematerial of this construction? Is it to be regarded simpls as a logical sbstraction, or has it reality as a distinct psychological factor? The question is a difficult one. Undoubtedly there is a danger to be guarded against in the tendency to "substantiate abstractions"- to assign to everr factor that may be distinguished in the analysis of thought's object a distinct psychical existence. The conception of an isolated sense-manifold needing to be corapelled into unity by the operation of the ego would seem to be for psychology a mischievous fiction resulting from some snch confusion between logical and psychological analysis. In the consideration of developed knowledge we may have occasion to distinguish an element of "pure difference"; we may take account of simple elementary sense qualities in abstraction from the relations in which they stand ; but it is now recognised that such sensational atoms are by no uneans primitive for psychology. It is not with such elements that the mind begins. As Prof. James has insisted we need invoke no special activity of a relating ego to reduce the sense-menifold to unity, for there is originally no such manifold to be unified.'

Yet, while rejecting the conception of a primitive senseexperience of isolated impressions, we seem nevertheless compelled to postulate the existence of a condition prior to what we understand by knowledge, and more properlydesignated sentience or feeling. In such a state we suppose there to be immediate experience of contents which at it later stage would be set over against the mind as objects. That duality which constitutes so fundamental a character of knowledge we can hardly but regard as having had an historical development. The distinction of a not-self from the felt self within the total of consciousness must hove been gradually attained. We cannot suppose that what is felt would in the most primitive condition appear as a subjective affection, but neither can we suppose it to be regarded as an object present to self. What we seem forced to postulate at the beginning of mental life is the mere sense of existence. the feeling of a somewhat in which the after-distinctions of knowledge are latent. ${ }^{3}$

Prof. James appears to oppose this view in his spirited

1 Primriples of Pyychology, vol. i.. p. 278.

= (\%. Bridlev, "Consciongness and Fxperience," MIND, N.S., vol. ii. 
account of the nature of primitive seusation. The infant, James declares, in his first dumb awakening to conscionsness encounters a something which " has objectivity, nnity, substantiality, causality, in the full sense in which any later object or system of objects has these things ". It is hard to understand what exact mesning can be attached to $B=$ sweeping a statement. One would suppose that in whatever manner "the categories of the understanding " might be contained in primitive sensation, it would most certsinly not be 'in the full sense' in which our thought later reslises them. It would appear however that by objectivity James sometimes intends no more than the absence of distinction between the me and the not-me. He speaks of the condition of minimal consciousness referred to by Prof. Herzen and others, where this distinction is lost, as being a retention of the sense of objectivity with lapse of subjectivity." Again. of the child's first experiences he says that they probably sppear in an sbsolute way, neither in nor out of thought. Only later, through repeated judginents of sameness and comparison of experiences, do we get the notion of realities externsl to, and independent of, the moment's conscionsness. ${ }^{3}$ The vigorous contention of Prof. James in favour of the possession by the most primitive sensation of the function of knowledge does not seem, then, to involve substantially a great difference from such a position as that of Bradley. If we retain the name of knowledge for the state where feeling is articulated by thought, where an object is distinguished from self and endowed with a significance beyond the moment, and where relations are recognised, still we should regard the feeling that preceded such knowledge as possessed of a positive content-as being something for itself - and we may be as ready as Prof. James to bow before the " miracle" contained in this fact. Elsewhere + James has declared that we may say a feeling "knows" a quality if we, as its critics, believe that outside the feeling is a reality which resembles it in content. This "self-transcendent function of cognition" which we, ss critics, recognise need not, James observes, be recognised by the feeling, and through its presence or absence the nature of the feeling is altered not a particle. Certainly in this sense we may grant to feeling the function of knowledge, even while holding that to thought and knowledge proper, in distinction

' l'risciples of Prycholosy, vol. ii., p. 8.

'Ibid., vol. i., p. $273 .{ }^{3}$ Ibid., p. 272.

"The Function of Cognition," HiNd, 1885, p. : 
from feeling, leclongs a self-transcendent function, or objective reference, which is no mere external relation recognised by an onlooker, but a conscious and most fundamental constituent of the nature of the state which possesses it.

A further point to be noticed in regard to feeling or sentience is that it nust be thought of as containing the material for the knowledge of relations no less than for that of qualities. Relations, like qualities, in order that they may become objects of knowledge, must be taken possession of by a constructive activity of thought; but that activity is guided and its result determined by the nature of what is first given in feeling or immediate experience. This point has been brought out with much fulness by Hobhouse.' We find it clearly recognised earlier, in the work of Lotze. Qualitative, local, and temporal relatiouships must all, Lotze insists, belong to the material supplied to thought." ${ }^{*}$ An activity of unique character is, he holds, required for the recognition of relations, ${ }^{2}$ but the nature of the relation which this activity shall reveal must be determined in immediate sensation.

4. In discussing the hypothetical primitive condition where all is feeling, Bradley has asserted: feeling does not cease to exist when cognitive consciousness begins: "everything experienced is on one side felt, and the experienced is also in part still no more than felt". The experienced is "always more than objects together with pleasure and pain "." So far as the truth of these statements is recognised they show the importance of the conception of feeling, not only for the doubtful reconstruction of the primitive mind, but all through the psychological account of the developed human consciousness. The first emergence of knowledge from the condition of mere feeling may indeed be a thing incomprehensible to us, bat within a mind where knowledge already exists, the passage of contents from the level of feeling to thought, from sentience to knowledge, is one of continuons occurrence.

Of a state of pure feeling it may be that we can have no experience. At all events we cannot, at the time or even iu memory, verify the existence of such a state. Nevertheless we experience in various ways approximations toward it, hints or indications sufficient to allow us to form an ides of the nature of feeling as a factor distinct, and in some measure separable, from thought. Thus, there are states of extreme

\footnotetext{
IThairy of Khourledefe, part i., ch. ii.

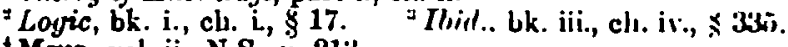

+Mrs, vol. ii.. N.8., p. 213.
} 
diffusion of attention where the mind seems to lose itself in a dull blank sense of existence in which no presentation stands out above the rest: there are states of excessive emotional disturbance-8uch distress as is referred to by Rossetti in a line that Bradley quotes:- 1

First 'twas fire in her breast and brain,

And then scarce hert, bat the whole world's pain,

-pain so overwhelming that it seems to involve no object, but is felt as a limitless spechless horror or oppression filling all the space of conscionsness. Sense-impressions, again, of too great intensity may have a similar stanning effect, extinguishing intellectual activity, and we have reports of cases where, under the influence of anæsthetics or during the course of a swoon, the usual distinctions of consciousness seem annihilated; thus Prof. Herzen describes such a state as " $a$ sense of existence in general without the least trace of distinction between the me and the not-me"."

More important for the present purpose than such experiences are those partial constituents of a total conscions state which seem not to rise above the level of feeling. When attention is engaged with some train of thought, or course of observation, the objects presented appear not to absorb the whole amount of consciousness. Beyond and around them there is feeling, having, as it seems, a positive content of its own, undiscerned, yet colouring the total state, which would be different for its absence or modification. Dr. Stout has termed this outlying portion of consciousness "anoetic". 3 It consists of such mental modifications as are not utilised, or but to a small extent atilised, in determining the reference of thought to an object. It offers material for possible acts of discrimination, since it involves differences which as they exist at the moment are not thought-distinctions but are merely felt. ${ }^{4}$ Special sensations which fail to receive attention, and, normally, the whole mass of organic sensation, exist in this manner. Floating imagery irrelevant to the train of thought may also form part of the felt backgroond.

5. From this "region of the subconscious" elements may pass into the circle of attention. As Prof. Sully observes, in speaking of such vague sensations, etc., they "may afterwards emerge into the full light of conscious-

1 Mind, vol xiii, p. 3.

"Quoted by James, I'xyclulugr!l, vol. i., p. 273.

= Analytir Psycholog!!, vol. i.. p. 50. 'Ibid., pl. 48 and 181. 
ness" "by ineans of a special direction of attention upon them; and as being susceptible of such elevation through attention he refers to them as "raw material for mind"." This phrase may from one point of view seem dubious; for certainly these elements detached from the thought of the moment are not wholly unmodified by thought. They owe very much of such character and influence as they possess to prior intellectual activity. This is plainly the case with the faintly suggested imagery that clings about thought, and hardly less so with the total mass of sensations from the environment, which, even at times when we seem wholly oblivious of them, appear to exert some depressing or stimulating effect which is in eccordance with our consciously formed habits and associations; while they cannot receive the slightest, most transitory glance of attention without being immediately interpreted for what they are.

Even the organic sensations which appear so little elaborated by thought undoubtedly enter into certain permanent mental constructions, the presentation of which they continually sustain or serve to renew. The self, with something of its habitual character and present mood, is sensed in the dim awareness of the bodily sensations. Even recent emotional experiences-pleasures or anxieties-seem to make themselves felt, during forgetfulness, in the faint reverberations of bodily disturbance which they have left behind. In what sense can we designate as mere feeling, or as raw material for mind, sensations into which the ideal interpretation is so closely wrought?. It is evidently only in a relative sense that we can so regard them. They are elements of feeling, not of thought, relatively to those contents which occupy the inner circle of attention. The act of thought or perception occurring at the moment has a certain degree of systematic unity which tends to exclude what is irrelevant, and thas to deprive it of significance. ${ }^{3}$ When attention is otherwise absorbed it seems to be only by a divergence of it-a real divergence, however slight, easy and momentary-that we bring out the objective meaning bolonging to the sensations from organism and environment. Yet when we do this we cannot believe that our judgment originates the feeling of these sensations as well as their interpretation. The feeling of them seems a persistent fact -a something recogniseble retrospectively in the tone of the preceding moment's conscionsness as well as in that of the present.

1 Human Hiuh vol. i., p. 73. $\quad$ " Ibid, p. 76.

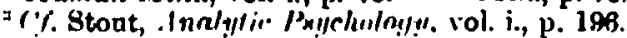


Mr. Shand has urged this point as being one continually brought out in the judgments of daily life. It is constantly believed that certain sensations and feelings precede the recognition of them: when discriminated they are judged to be old factors in experience. There seems no sufficient resson for supposing such judgments illusory.'

We should maintain, then, that such undiscriminated modifications of consciousness show us cases in which the functional or cognitive aspect of presentation is in abeyance as compared with that aspect which may be spoken of as mere psychical existence or feeling. Such immediately experienced modifications offer " raw material " to the present thought, in that it lies with that thought-the attentionprocess of the moment-to bring out their significance, to assign them a place in the organised texture of Reality, to realise their idesl relations. It seems important to recognise that even what is merely felt connot be independent of the results of past experience. Modern psychologists have discarded the ides of the unmodified impression, the simple resalt of a stimulus, offered as a datum for thought. In the structure of the brain every experience must leave its " unimaginable touch," modifying future response ; so that, even in the absence of the elaborating process of attention, what is felt will be other than it would have been in a brain undeveloped, or modified by a different course of experience. Yet while maintaining the fact. of such modification-taking account of the effects of past thought-activity as well as of past sensation and impulse-we may none the less maintain the distinction, at any given point of time, between the mere existence of presentational material on the one hand, and on the other, its recognition and utilisation in the process of judgment.

6. For the completer elucidation of this distinction, the nature of the judgment-process must be somewhat inore fully considered; but, before passing to this topic, it may be well to bring ont a further point in regard to presentational modifications as relatively unatilised by thought.

Reference has been so far made chiefly to subconsciuus factors which may be spoken of as outlying parts of consciousness. Such factors may fail to be taken up into judgment merely because attention is otherwise uccupied, and, if so, may be identified upon its release by the effortless repetition of a familial thought-activity. But we frequently experience acts of discrinuination of is sumewhat different

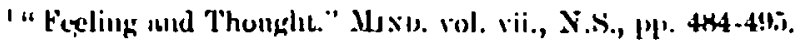


character. Presentations which had formerly received attention only wholes are broken up into their factors and these become for the first time, and perhaps with considerable effort, distinct contents of thought. The question has been much argued whether in such a case the elements discovered can be said to have been previously. felt within the whole. Prof. James has denied this. Whep we come for the first time to discriminate factors within an experience, he asserts such factors are absolutely new psychid modifications. ${ }^{1}$ It is properly the objective fact, not the presentation, that is analysed." An objective thing we regard as having all along the qualities which we gradually come to discover, but while the thing remains the same the thoughts of it, as a whole and again as anslysed, are 'two absolutely different peychoses '." This is surely going too far even as a reaction againgt the fallacies committed by the upholders of "the anconscious". It is unquestionably trae, as James urges, that a certain thought does not, simply becanse it refers to en identical object, contain "in an unconscious way," all that may be known to a later thought of that object. Dismissing those cases where actual new sensations are gained by closer examination, the later thought, in a case of purely mental analysis, will contain new elements in the way of suggested symbols, ideas of relation, etc. Yet while taking account of such additions and fully admitting the fundsmental character of the distinction between a presentation as discriminated and as andiscriminsted, we mast surely admit an element of likeness between the earlier and the more developed thought that is of importance also. Dr. Stout has described this element of likeness as a 'correspondence'. If a later state is to know and adequately represent an earlier unanalysed state there must be a correspondence of each thought-distinction in the later to a felt difference in the earlier:" Mr. Hobhouse, discussing the same subject, has spoken of the original element of feeling becoming "interwoven" with the relations subsequently discerned. The "clearer" consciousness contains what was present to the more obscure, only further determined by fresh characteristics.

These accounts seein to provide au interpretation more adequate than that of James for what we frequently feel when looking back npon an unanalysed experience in the

\footnotetext{
'Brychology, vol. i., p. 173.

Ihich., p. î23 note. ${ }^{\prime}$ Jhid., p. 489.

A Analyti: Puycholoyy, vol. i., p. 61.

'Thenry of Knnwledge, p1 133-64.
} 
light of new distinctions. The pleasure that often accompanies successful mental analysis, especially in the case of westhetic impressions, seems due not simply to the fact of knowing better " the objective thing," but slso to the sense of completion or fulfilment of something actually present, as it were in germ, within the earlier state.

For example, I meet with an analyeis of the grotesque, as ' the comic with a flavour of the terrible added, to give a grim dignity and save from triviality'. I have not previously attempted any auslysis of such instances of the grotesque as have impressed me (s8y, some of the strange carved forms on a cathedral), but recalling them as they existed in memory I seem to find the elements indicated unmistakably present within them, though hitherto unseparated and unnemed. It is the development-the illumination by thought of a content already possessed by the mind that seems to constitule the characteristic note and peculiar pleasure of the experience.

In simpler instances such as that given by Stumpf-the analysis of the taste of peppermint-there is a similar experience of correspondence, feature for feature, of elements felt within the whole, or 'synthetically' to characters afterwards discriminated, and set apart by naming.

7. We have now to attempt some consideration of the question what is involved in the transition from feeling to knowledge? What is the essential forn or structure of the judgment process into which the elements of sensational experience must be taken up that they may become known? This question has been approached by many writers as part of the doctrine of Apperception. Freed from the dubious metaphysical implications with which it has been sometimes connected, the tem apperception serves to desiguate the process through which a presentation becomes modified and attains significance in accordance with the results of past experience. Apperception has been distinguished from attention by Wundt as referring to the changes set $\mathrm{up}$ in ideational cuntent, while attention may be used rather of the subjective sensations and feeling which accompany the change (Lectures, xvi., $§ v$.). Similarly Baldwin has spoken of apperceptiou as attention considered in respect of its discriminating, selecting and relating results.' The problem of ipperception thns conceived comes closely into touch with logical discussions as conducted in the coimprehensive spirit of such logicians as Bradley, Bosanquet, Hobhouse:

It appears inevitable that in dealing with the nature of

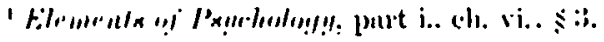


thought, psychology and logic, in spite of their different points of view, should largely interpenetrate. As Bosanquet says,' the aspect of ideas as 'meanings' as elements of a world of knowledge, is one which, though distinct from their nature as psychical occurrences, cannot but affect that nature, and wust not therefore be ignored by the psychologist ; while again, the logician, in considering the nature of objects ass knowledge, and the validity of thought processes, cannot but be thrown back upon the nature of such thought and knowledge as concretely embodied in the action of individual minds. In our present problem we are concerned with ideas in both their aspects-both as meanings and as psychical occurrences-and we may hope to obtain assistance from the discussions both of logic and of psychology.

As a definition of judgment we may accept that given by Bradley : "Judgment proper is the act which refers an ideal content (recognised as such) to a reality beyond the act"." This definition brings out clearly the distinguishing characteristic of judgment-and under the head of judgment we include every act of thought and knowledge-as contrasted with mere feeling or sentience. In judgment there is a reference beyond what is immediately felt or given: there is, as Stout expresses it, ' an acknowledgment of objective existence,'" a reference " to something which as the thinker zeans or intends it is not a present modification of his individual consciousuess" (p. 47). It is as a condition of the attainment of this objective reference that the cleft must be made in consciousness which we have spoken of as the distinction of self and not-self. In speaking of such a distinction it is not mesnt to imply that there is at first any ides of the self as 'a permuanent subject of experience,' possessed of certain powers and attributes. Self as an ideal construction appears to be a considerably later attainment than the perception of a world of objeats. But before there can be such objective perception it would seem that the distinction must be made which involves the first dim consciousness of self through contrast with the not-self. There must be awareness of a something as relatively permanent and as coercive, in distinction from the sensitive act that occurs at the moment and suffers control. It is difticult to find language which shall be free from luisleading associations in expressing the l/are essentials of such a distinction. Lot\%e has describer that act of objectification which constitutes the

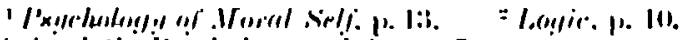

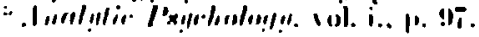


starting-point of thought as the separation of something before unseparated-on the one hand 'our sensitive act' or the 'condition which we undergo'; on the other, 'a something which has its being and its meaning in itself, and which continues to be what it is and to mean what it means whether we are conscious of it or not' (Layic, bk. i., ch. i., § 2). Lotze has been adversely criticised by Prof. Jones for his error in supposing that we first know the subjective state. as such, and then pass over from this to the object. It seems doubtful whether Lotze's language really necessitates this interpretation. His words above referred to-the separation of "something before unseparated"-would seem to lend themselves rather to the view expressed by Bosanquet ${ }^{1}$ when he says that if the prinnitive mental image is "merely such" -merely subjective-that is because it is "not yet taken for such". Its content or meaning is not separated from its mere existence as psichical fact, so that its occurrence can be used as a sign or reference: to something beyoud. There is no judgment or assertion of objective truth in the mere experience of sensations and images. In order that the claim to truth may be made and objectivity be recognised, the possibility of error luust have made itself felt. The mind must be capable of distinguishing in some rudimentary way between a mere mental suggestion and the Reality by which such a suggestion may be either rejected or endorsed.

8 . It is by considering the active character of conscions life from the first that we may get some faint indication of the way in which the distinction we are considering might arise.

Before any clear imagery is possible it would seem that there must still be felt what we might tenn a 'forward trend' in consciousness. The simplest activities of animsl life are probably accompanied by strivings which are felt, although blind as to their end, and wheu these activities have been frequently repeated they can hardly remain completely blind. About the impressions which excite then will gather a mental supplement of some kind, and sonu. feeling of anticipation will accompany the inovernents of the organism. When the mentally supplied elements within these "feeling-groups" = have become sulficiently stable there will arise the possibility of conflict in a case where the movement of the organism fails to bring about the accustomed result; and such conflict we mav suppose to senerate

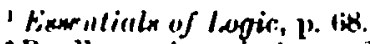

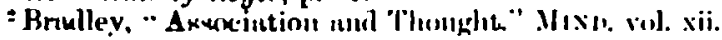


the recognition of the idea as such, on the one hand, and of a reality beyond it. However doubtfally we may regard this attempted sketch of a primitive experience, yet it may serve to illustrate to us in simple form the nsturt of the factors present in developed judgment as we know it. The Reality which clashed with the "feeling-group" woulc be apprehended as coercive; it would stand out as somethic foreign to the struggling sensitive self ; and with that, the idea would first begin to appear and be known as an ides, that is, as something suggested or maintained within the self, but which is in its nature incomplete, looking out toward a world beyond it for acceptance and endorsement. It is no longer mere fact in its own right hut makes claim to truth. In the aftirmative judgment the validity of this claim is soserted: the cleft between reslity and mental content is besled again, and the idea becomes fact, but not in the old immediste undistinguishing fashion. Adopting somewhat mythological language we may say that Reality, while accepting the suggested predicate, maintains the power to reject.

9. We may notice briefly how the fundamental distinction within judgment becomes elsborated in the developed stages of knowledge. The reslity which we 'encounter' in perception becomes extended indefinitely through time and space; it becomes qualified by the results of inuumerable thought-activities, and is regarded as capable of appropriating new predicates indefinitely. Especially important is the point that it. is a reality common to self and others. As it controls my subjective activity so it controls that of others; while in one sense the self-when I come to know myself as a person among persons-is included, along with them, in the sum total of Reality. But through all this yualification and extension, the Reality for me-the ultimate subject of my thought and knowledge-remains rooted in immediste feeling. It is the unique Reality against which I measare myself from moment to moment in action, and which I encounter in sense here and now. In Bosanquet's words, the whole structure of Reality " hangs fron my present perception ".

As the knowledge of the subject of judgment develops so we may trace a corresponding development in the predicate. or the 'merely ideal' aspect of judgment. It is impossible, Bosenquet observes, to dispense wholly with the conception of an objective world, or world of meanings, distinct from the resl world of facts. This conception is indeed, he insists, an abstraction. Yet we are frequently compelled to consider 
ideas, by help of abstraction; in respect of those relations which especially determine them, as detached fragments of knowledge not definitely referred to a place in the one individasl system of reality (Logic, p. 5). In affirmative judgment the ideal content is indeed, as we have seen, referred to, and united with, Reality ; it becomes the adjective of concrete fact, yet in its function as adjective, or ideal content, it may be regarded as belonging to a system of predicates-a world of qualities and relstions sustsined in the minds of thinkers rather than concreted in the actual existence of things. It is as such a system of predicates that Lotze has explained the world of Ideas conceived by Plato. ${ }^{1}$ In the world of Ideas those knowable contents which experience presents to us in ceaseless flux and bewildering irregularity are bound together by the efforts of the mind into a system of anchangeable conceptions-a world in which the intellect may feel itself at home and unperturbed (cf. Plato, Phado).

This system of predicates, like the Reality from which it is abstracted, is a common possession; it is essentially the work of collective mind; and as embodied in language is participated in by every individual who attains to the power of speech within the community. Again one must refer to the difficalty in expressing such conceptions as these in a manner not open to misconstruction. Prof. Jones has argued vigorously against the abnse of this notion of an ideal system of knowledge distinguished alike from the one concrete Reality and from idess as occurrences in individusl minds." We must of course admit, as Prof. Jones, and Lotze before him, have contended, that such a system can exist neither as concrete things exist, nor as the presentations exist that occur from moment to moment within our minds. Yet none the less the 'transitional conception,' as Bosanquet has termed it, of such a system appears necessary in order to describe the function of idess in judgment,- - to express that power of identical reference and rational agreement among many minds which enables each individual not only to make use of his own sensuous experience but to transcend it, lesming from others, and co-operating w with them in the advancement of universally valid knowledge.

This then we conceive to be the form of judgment as manifested continuously within the "waking human conscionsness". There is awareness of a real world brought home to the mind in sensation, but extended and qualifier

'Loyic, bk. iii., ch. ii.

I "Idealiam and Fpistemology;" MIND, vol. ii., N.S. 
through ideal coustruction. Within this reality there will be usually some point (which may or may not appear as given in perception), which stands out as the topic of attention, or subject of thought. At this point we attach, or experimentally apply, the ideal contents which are brought before us by the working of our minds, in attentive effort or in more passive reverie, or again as determined by changes in a physical object of perception. As we judge, making application of ideal predicates to the fragment of reality with which we are specially occupied, we unite this by means of relations to much that lies beyond it, we give it a place in the idesl world of knowledge.

10. As has been observed above, this process of judgment is, from the more psychological point of view, described as apperception The impression or image, which, as it first nises into consciousness may be merely felt, is apperceived when it is taken up into the systematic unity of the judginent process, and related, either to conteuts which are already present in thought, or to others among those of the inind's intellectual possessions which are not too remote for revival. It is not of course intended to suggest that in the case of every presentation a feeling of it precedes its atilisation in judgment. Frequently the occurrence of a sensation or image and its complete interpretation, so far as the noment's purpose requires, sppesr absolutely coincident; or, if a gradual process of interpretation does take place, still the presentations which acquire fuller meaning are from the first invested with a considerable degree of idesl aignificence. Since however our present interest lies in the distinction between clear cognitive conscionsness and what is relatively mere feeling, it is with certain special cases of apperception that we are more particularly concerned :- - those namely in which the interpretative process is, for an ingtant or longer, obstructed; thus affording time for the experience of transition from one mode of consciousness to another, from feeling to thought and understanding. We have illustration of such a transition when some shock of external impression bresks in suddenly upon us, and we "collect our minds " to desl with it : or when our attention is drawn by a dim feeling as of some image suggested but unrecalledsome forgotten word, or scene, or melody - which hovers before us impalpable, characterless, till suddenly by a happy Hash we secure it. In sach experiences we have vividy emphasised the contrast between that degree of distinctness which we demand of every mental object-some setting in the world of knowledge, some assignable character and rela- 
tions-and the condition of a mere feeling, unrelated and unnamed. It is true that our disquiet in the presence of such feeling only arises when we actually apply the form of knowledge, and find ourselves for at least some brief moment of effort unable to compel within it the presentational matter experienced; i.e., unable to accomplish in this particalar case the work of distinction and relation ordinarily achieved in the effort of attention. Constantly we may experience: anoetic sensations, feelings that are not known; such feelings cannot disquiet as until we seek to know them, and they are then, by that very fact, no longer completely anoetic. Still it is in the transition-the seoking and coming to know-that we seem best able to realise, in a relative war, through contizst, the lower grade of consciousness. In the tarning of attention,-in the anspoken question, "What is this ?" whether the "this 'be an element that has arisen in the field of inattention, or an element within a presentation attended to formerly only as a whole-we experience the application of the form of knowledge. We assign to the obscare experience a place as a feature of reality occurring here and now, and we require of it moreover that it shall reveal some character which may bring it into touch with the system of our knowledge. It must be assimilated to past experience; either recognised through the revival of some distinct individual image, as when we recover the particalar memory that has haunted us; or else defined by means of some general concept, as when we identify the wailing sound that has "rang in our ears" as the cry of u sea-bird, or analyse out and name a flavour within a complex impression of teste, or discover in a verse of poetry the subtle alliteration and assonance that had been to us formerly only a vague indescribsble charm. In all such cases the apperceptive process is accomplished os the felt or given element is identified with some idesl content-some fixed 'meaning' which is regarded as having its own place in a system of fixed and permanent relations independent of the momentary act that recognises them.

11. Bo far we have spoken of the apperception-process only as it takes place apon the thought-level. But below the level of thought there is also a process of organisation of the material of experience: new impressions become modified through the resalts of past activities although such results: are not elaborated into the form of concepts, nor are relations between new and old conscionsiy establighed.

It is in the most immediate connexion with bodily movement that sach primitive intellectual activity is carried on. 
In the case of a creature that has not attained the power of thought the process of lesming by experience appesrs to consist of a sort of gradual "stamping in " of successful modes of behaviour by means of the pleasurable excitement which they produce I At any stage of development the cresture is possessed of certain habits or tendencies to particular kinds of movement, and these, exercised, as Prof. Baldwin says, "in a heightened or excessive way" under the stimulus of partially new externsl impressions and of felt organic craving, form the material from which saccessfal variations are selected. It seems certain that the process although intelligent need involve no exercise of thought proper: the impressions are assimilated for parposes of action, but not brought ander general ideas. We ourselves have experience of forms of mental activity in connexion with bodily movement which appear to a large extent independent of the employment of idess. The results of such activities are preserved in the form of habits wrought into the physical organism; there is acquired what Prof. H. Sidgwick has described as " an adaptation of the muscular to the sensitive and cerebral system, which is not properly knowledge".?

Thus in mástering a game of skill, sach as teunis or billiards, motor adjustrnents are performed, and habita of delicately adspted reaction learned, while neither of these reactions themselves, nor of the occasions which prompt them, do we ever attain any conceptual knowledge of corresponding delicacy. . We do not of course abandon altogether during such exercises the conceptual attitade. We continue to be guided in a general way by idesl plans and purposes which we could frame to ourselves in language; we inake use also of rules and of terms, both technical and of common description, which serve as concepts under which to bring the various efforts and occurrences of the game. Yet the judgments which are thus formed go but a very little way toward expressing the exact character, the minute differences, of the stimuli as these are operative in determining our movements, and of the responsive movements themselves as they are felt to take place.

We may, if we use the term with wide extension, speak of apperception as taking place in regard to those features of impression to which we simply learn to adapt suitable inoveIuent: such festures become incorporated into a system of

1 Cf. Thorndike, quoted by Stout, Mtenual, pp. 261, 263 .

I "Theory and Pructice." MInd, vol. ir.. X.S., p. 370. 
mental tendencies through which they attain a practical valne, but we must distinguish this case from that in which the system itself is an object of apprehension for couscionsness, and it is thus into a tissue of apprehended relations that the impression is received. It would seem to be in this latter case only that we can regard the assimilated-presentation as becoming an element in knowledge proper.

As compared with this higher reflective form of cognition we may speak of the process of acquiring bodily skill as being commonly in large messure subconscious. Prof. Lloyd Morgan has so described it; using tbe term "marginal in conscionsness" to express the condition of those sensations of motor adjustment which are at once of such importance for action and so little dealt with by thought.'

12. While endeavouring to distinguish the ective process of organisation which may take place within the sphere of sentience from the organisation of knowledge proper, we have said little concerning another contrast which is perhaps more frequently emphasised when grades of conscionsness are discussed, viz., that between the high and vivid degree of feeling present while new motor combinations are being learnt, and the slight degree of mental distarbsnce which accompanies habitual movements. In habitual movement not only is there sbsent such thought-activity as in the haman mind attends, though it does not fully penetrate, the sentient processes of motor acquisition, but slso there is a great dimination in the amount of mere feeling or sentient disturbance. The notor adjustments are performed more readily and economically: the body of sensation contributed by sympathetic strains and contractions of other parts of the inuscular system has disappeared: within the brain changes have probably taken place facilitating the passage of the nervons impulse. Thus the mental accompaniment of the motor process occupies less room in the mental area." It no longer offers such resistance as formerly to the occurrence of other mental activities. It is diminished, or has almost disappeared in respect of its mere psychical existence as felt.

When we contrast with this the state experienced during the original process of motor acquisition - the felt strain of body and absorption of mind-it seems appropriate to describe the latter process as one in which consciousness is vivid or intense, present in a very high degree. Is there any

Introduction to Comparatite Pyycholoyy, p. 168.

" rif. Bradley, "Intensity of Paychical States," JIIND, 189i. 
conflict here with the statements of the preceling discussion in which the process of motor acquisition was designated lergely subconscious? There is no conflict when we distinguish the different principles involved in the two kinds of contrast. In spesking of subconscious and of distinctly conscious presentations. we have been estimating the mental state in respect of its value for thought; we have inquired bow far its content is reflectively utilised, related and referred as an adjective to reality. But now in this contrast of modes of consciousness as faint and as intense a different standard is adopted. The mental process is considered in respect of the amount of feeling-disturbsnce involved, or of the mental energy absorbed to the exclusion of other processes. In estimating a state successively according to these different standards we may find that the positions assigned to it by no means coincide. A process of motor acquisition, as has been observed above, may be little if at all penetrated by thought, but may yet be absorbing and keenly felt; while on the other hand, as will be considered later, a true process of thought--the apprehension of a content as ideally related and significant-may come to take place with but swift and slight disturbance of conscionsness, so that doubt is even possible whether the ides is actually presented at all. It hecomes, as the result of repeated thought-activities, an 'implicit' element in conscionsness.

(To be concluded.) 